\title{
Metodologías otras desde la perspectiva decolonial
}

\author{
María Noel Míguez Passada1, Ivana Fernández López ${ }^{1}$ y Karina Silva ${ }^{1}$ \\ 1 Universidad de la República, Uruguay | marianoel.miguez@cienciassociales.edu.uy; \\ iviferlopez@gmail.com; karinasolla11@gmail.com / https://orcid.org/0000-0001-8233-1329; \\ https://orcid.org/0000-0000-0000-0000; https://orcid.org/0000-0000-0000-0000
}

\begin{abstract}
Resumen: Introducción: A través de la presente de los trazos que siguen a continuación les invitamos reflexionar colectivamente sobre metodologías otras desde la perspectiva decolonial. Objetivo: Compartir metodologías otras que recuperan el encuentro de saberes plurales como sustancia medular para el despliegue de los procesos decolonizadores (investigaciones) desde la perspectiva decolonial. Métodos: En el hacer decolonial (metodología) surgen diversas acciones / huellas decoloniales (técnicas), las cuales habilitan al pienso colectivo e intercambio de saberes plurales. Ello enriquece todo el proceso decolonizador que se despliegue desde esta perspectiva, siendo todos/as los/as sujetos/as que de éste participamos protagonistas activos/as. En esta procesualidad se van materializando acciones / huellas decoloniales, como ser: conversares alternativos, contemplares comunales y reflexionares configurativos, las que permiten reflexionar desde formas otras lo histórico-social. Resultados: Los despliegues del hacer decolonial, a través de sus acciones / huellas decoloniales, nos permiten generar encuentros reflexivos entre sujetos/as plurales hacia las producciones de conocimientos colectivos, superando hegemonías interiorizadas y reproducidas desde lógicas extractivistas del saber, ser/estar y poder entre los/as sujetos/as de los procesos decolonizadores. Ello nos permite transitar hacia la superación de las colonialidades del saber, poder y ser/estar, así como de las lógicas de señorío, propias de la modernidad colonial. Las utopías hacia la construcción de sociedades otras comienzan a tornarse parte constitutivas de nuestras posibles y reales materializaciones. Conclusiones: Generar formas otras de comprensión de la realidad social, tal como las que se plantean desde la perspectiva decolonial, abre nuevos horizontes de sentidos que nos reubican como sujetos/as plurales en entramados pluriversales, donde los/as protagonistas somos los/as sujetos/as que encarnamos los distintos procesos decolonizadores.
\end{abstract}

Palabras clave: Investigación Cualitativa; Perspectiva Decolonial; Hacer Decolonial; Acciones/Huellas Decoloniales.

\section{Methodologies others from the Decolonial Perspective}

Abstract: Introduction: Through the present outlines that follow below, we invite you to reflect collectively on methodologies others from the decolonial perspective. Objective: Share methodologies others that recover the encounter of plural knowledges as a core substance for the deployment of decolonizing processes (researchs) from the decolonial perspective. Methods: In the decolonial doing (methodology), various decolonial actions / traces (techniques) arise, which enable collective thinking and the exchanges of plural knowledges. This enriches the entire decolonization process that unfolds from this perspective, with all the subjects that participate in it as active protagonists. In this process, decolonial actions / traces are materialized, such as: alternative conversations, communal contemplations, among others, which allow us to reflect on the historical-social from ways others. Results: The deployments of the decolonial doing, through their decolonial actions / traces, allow us to generate reflective encounters between plural subjects towards collective knowledge productions, overcoming internalized and reproduced hegemonies from extractivist logics of knowledge, being and power among the subjects of the decolonization processes. This allows us to move towards overcoming the colonialities of knowledge, power and being, as well as the logics of lordship, typical of colonial modernity. The utopias towards the construction of societies others begin to become a constitutive part of our possible and real materializations. Conclusions: Generating forms others of understanding of social reality, such as those posed from the decolonial perspective, opens up new horizons of meanings that relocate us as plural subjects in pluriversal frameworks, where the protagonists are the subjects who embody the different decolonizing processes.

Keywords: Qualitative Research; Decolonial Perspective; Decolonial Doing; Decolonial Actions/Traces. 


\section{Introducción}

Desde el Grupo de Estudios sobre Discapacidad (GEDIS) de la Facultad de Ciencias Sociales (FCS), Universidad de la República (Udelar), Uruguay, les invitamos reflexionar colectivamente sobre metodologías otras ${ }^{1}$ desde la perspectiva decolonial de nuestro Sur Global $^{2}$.

El objetivo de los trazos que siguen a continuación está en compartir metodologías otras que recuperen el encuentro de saberes plurales como sustancia medular para el despliegue de investigaciones desde la perspectiva decolonial. Para ello, de aquí en más, retomamos las formas de nombrar que utilizamos desde esta perspectiva, ya que nos irán ubicando en el correlato con contenidos otros, en principio, en la decolonialidad del saber. En este sentido, iremos desandando entramados del hacer decolonial (metodologías) y algunas de sus acciones / huellas decoloniales (técnicas) en los procesos decolonizadores (procesos investigativos).

La perspectiva decolonial surge desde las entrañas de nuestro Sur Global, cuan "era pariendo un corazón" (Rodríguez, 1968), hacia mediados de la década de los '90 del siglo XX. Varios/as autores/as de nuestro Sur Global comienzan a interpelar fuertemente las lógicas coloniales del ser/estar, saber y poder, las cuales veníamos interiorizando y reproduciendo acríticamente, como un "en-sí" no cuestionable.

Para la especificidad de nuestra América Latina, posiblemente la imposición devenida de tener que "celebrar" los quinientos años del "descubrimiento" de América, en 1992, haya abierto varias heridas coloniales que aún estaban acalladas.

En este escenario, distintos/as autores/as de varios espacios académicos de nuestro Sur Global latinoamericano fueron aunando miradas, sentires y pensares hacia formas otras de comprender la realidad, poniendo en tensión los instituidos coloniales en lo teóricometodológico, ético-político y epistemológico-ontológico. A través de sus producciones de conocimientos otros, nos fueron invitando a (re)pensar(nos) y (re)sentir(nos) como sujetos/as "válidos/as"3 en nuestras formas otras de habitar el mundo, de generar conocimientos y de desplegarnos en lo histórico-social. De esta manera, "viejos conceptos con nuevos significados comienzan a ponerse en danza en las producciones de conocimientos" (Míguez, 2021, p. 3).

En lo más específico de este artículo, iremos hacia el hacer decolonial. Más concretamente, presentaremos algunas acciones / huellas decoloniales, entre las que encontraremos: conversares alternativos, contemplares comunales, reflexionares configurativos. Éstas acciones / huellas decoloniales nos permitirán ir reflexionando colectivamente desde formas otras de analizar lo histórico-social, así como de generar praxis transformadoras a través del protagonismo de quienes históricamente han sido extractivamente ${ }^{4}$ sentenciados/as a ser objetos en los procesos de investigación coloniales modernos.

\footnotetext{
${ }^{1}$ Cada vez que utilizamos formas de nombrar traspasadas por la decolonialidad, las explicitamos a través de cursivas, no solo como interpelación a quienes estén leyendo, sino, también, como acto político nuestro.

2 El Norte Global y el Sur Global nos remiten a diferencias epistémicas en las formas de conocer, más que a geolocalidades de un Norte y un Sur. En este sentido, en todo Norte Global hay un Sur Global, así como en todo Sur Global hay un Norte Global. Quienes nos posicionamos desde la perspectiva decolonial, nos sentimos tan lejanos/as del Norte Global de nuestro Sur, como cercanos/as al Sur Global del Norte. Nos aúnan dolores por avasallamientos, extractivismos, sometimientos, denostaciones, subalternidades devenidas de las imposiciones modernas coloniales (Míguez, 2021).

3 "Validez" medidada, exclusivamente, por las lógicas coloniales del ser/estar, saber y poder.

${ }^{4}$ Las lógicas extractivistas remiten al saqueo y/o expropiación de sujetos/as, comunidades, saberes, formas de habitar el mundo, etc. Según Grosfoguel (2016), éstas se materializan en "extractivismos epistémicos" y "extractivismos ontológicos", los cuales vincula con los "extractivismos económicos", tan explícitamente desplegado por la modernidad colonial.
} 


\section{EI Giro Decolonial. Hacia la Superación de las Colonialidades del Ser/Estar, Saber y Poder}

Para quienes habitamos el mundo desde nuestro Sur Global latinoamericano, las imposiciones coloniales modernas del ser/estar, saber y poder nos vienen meciendo desde hace varios cientos de años, adormeciéndonos en nuestras propias esencias para que las apariencias coloniales continuen sus diversos extractivismos. ¿A cuáles extractivismos nos estamos haciendo referencia? Pues, no solo a los arrasadores extractivismos de nuestras tierras y comunidades a través de las colonialidades del ser/estar y poder; sino, también, a los extractivismos desde las lógicas coloniales del saber. Sobre estos últimos estaremos pensando conjuntamente a través de las líneas que siguen a continuación. Pero, primeramente, creemos sustancial trazar algunas pinceladas sobre las colonialidades del ser/estar, saber y poder, así como nuestras procesuales decolonialidades a través del llamado giro decolonial.

Las colonialidades del ser/estar hundieron sus raíces en 1492 y se fueron imponiendo salvajemente a través del discurso imperial de la "salvación" de quienes estábamos en nuestras tierras, habitándolas según nuestras esencias, confluencias y apropiaciones. Los Hermanos Berbel (s/d), a través de su canción "Amutuy" ("Vámosnos"), surgida de las entrañas de la patagonia, al sur de nuestro Sur, nos ilustran con sus versos el dolor de las imposiciones coloniales del ser/estar: "Pisotearon mis credos / Y mi forma de ser / Me impusieron cultura / Y este idioma también". No hubo nada que nos dejaran en nuestras formas de habitar el mundo desde nuestras pluralidades. Se apropiaron de todo y de todos/as, dando cuenta de los extractivismos predichos. Y siempre con el manto reproductor de las lógicas de señorío $0^{5}$ propias de la modernidad colonial: "La colonialidad del ser/estar deviene de las imposiciones coloniales de habitar el mundo según las lógicas de los/as colonizadores/as, barriendo todo atisbo de formas otras de ser y estar en éste" (Míguez, 2021, p. 5).

Las colonialidades del saber van estrechamente ligadas a las colonialidades del ser/estar. Éstas remiten a las imposiciones en las formas de conocer, pensar, producir conocimientos, otorgar valores (a estas producciones) y valías (a quienes las despliegan). A su vez, van intrínsecamente relacionadas con las lógicas de señorío y los extractivismos de saberes de los/as sujetos/as plurales que hacen a los procesos de investigación que se despliegan desde los instituidos de la modernidad colonial y su "saber científico".

Con el inicio del colonialismo en América comienza no sólo la organización colonial del mundo sino -simultáneamente- la constitución colonial de los saberes, de los lenguajes, de la memoria y del imaginario. Se da inicio al largo proceso que culminará en los siglos XVIII y XIX en el cual, por primera vez, se organiza la totalidad del espacio y del tiempo -todas las culturas, pueblos y territorios del planeta, presentes y pasados- en una gran narrativa universal. En esta narrativa, Europa es -o ha sido siempre- simultáneamente el centro geográfico y la culminación del movimiento temporal (Lander, 2000, p. 6).

Las verdades absolutas del saber moderno colonial, quedan enmarcadas en tales lógicas, generándose universales construidos por el Norte Global según sus escenarios teóricoepistemológicos. Ello lleva a la lineal desacreditación de todo cuanto se aleje de tales "verdades". El concepto de "verdad" (aletheia), tan enaltecido por los/as teóricos/as del Norte Global, aparece desde una totalidad colonial, no habiendo espacio para "las huellas de la herida colonial desde donde se teje el pensamiento decolonial. Puertas que conducen a otro tipo de verdades cuyo fundamento no es el Ser sino la colonialidad del Ser, la herida colonial" (Mignolo, 2007, p.29)" (Míguez, 2020, p. 28).

5 La modernidad colonial dividió "el mundo entre jerarquías de señorío y distintas formas de esclavitud basadas, ya no en diferencias étnicas o religiosas, sino más propiamente en diferencias presumidamente naturales, esto es, ancladas en la corporalidad misma de sujetos considerados como no enteramente humanos" (Maldonado Torres, 2008, p. 65). 
Lo anterior va de la mano con las colonialidades del poder, en tanto, para el saber moderno colonial, las relaciones son definidas previamente y parecen contener un fuerte carácter a-histórico o, como Quijano (2007) denomina: transhistórico.

La perspectiva eurocéntrica, en cualquiera de sus variantes, implica, pues, un postulado históricamente imposible: que las relaciones entre los elementos de un patrón histórico de poder tienen ya determinadas sus relaciones antes de toda historia. Esto es, como si fueran relaciones definidas previamente en un reino óntico, ahistórico o transhistórico (Quijano, 2007, pp. 97-98).

Esto lleva, por ejemplo, a que la conjunción modernidad - capitalismo se inscriba como asociación estructural y natural. Lejos de natural, hunde sus raíces en la construcción del pensamiento moderno colonial occidental expandido capilarmente como el único válido y posible. Ello no solo interpela cómo las intersubjetividades se despliegan y le dan sentido a su ser/estar y saber, sino, principalmente, demarca las relaciones de autoridad y sus ejercicios a través de las colonialidades del poder.

Llegados/as a este punto, entra en escena el llamado giro decolonial, el cual propuso, desde sus inicios, "la apertura y la libertad del pensamiento y de formas de vida-otras (economías-otras, teorías políticas-otras); la limpieza de la colonialidad del ser y del saber; el desprendimiento de la retórica de la modernidad y de su imaginario imperial" (Mignolo, 2007 , p. 30). Con este giro decolonial, los/as primeros/as autores/as de la perspectiva decolonial comienzan a poner en el tapete que la colonialidad fue ( $y$ es) una de las formas principales para el despliegue de las lógicas mundiales de distribución del poder en el capitalismo de la modernidad. De esta manera, "todo fenómeno histórico-social consiste en y/o expresa una relación social o una malla de relaciones sociales" (Quijano, 2007, p. 103), en un campo de relaciones que lo trasciende (Míguez, 2020). De ahí que nos hayan planteado el concepto de totalidad histórico-social.

(...) con América el capitalismo se hace mundial, eurocentrado y la colonialidad y la modernidad se instalan, hasta hoy, como los ejes constitutivos de este específico patrón de poder. En el curso del despliegue de esas características del poder actual, se fueron configurando las nuevas identidades sociales de la colonialidad (indios, negros, aceitunados, amarillos, blancos, mestizos) y las geoculturales del colonialismo (América, África, Lejano Oriente, Cercano Oriente, Occidente y Europa). (...). Ese modo de conocimiento fue, por su carácter y por su origen eurocéntrico, denominado racional; fue impuesto y admitido en el conjunto del mundo capitalista como la única racionalidad válida y como emblema de la modernidad (Quijano, 2007, p. 94).

Según Mignolo (2007), si aceptamos los argumentos predichos en torno a las colonialidades del ser/estar, saber y poder, así como sus deconstrucciones a través del giro decolonial, ya nos encontramos posicionados/as desde una perspectiva decolonial. Esto nos permite traspasar dialécticamente las lógicas moderno-coloniales, fundamentalmente, en lo que hace a las producciones de conocimientos y las "valías" de unos/as y otros/as.

La perspectiva decolonial, a pesar de su heterogeneidad a la interna, se funda en cinco enunciados teóricos fundamentales, tal como lo plantea el Grupo de Estudios sobre Colonialidad (Gesco, 2012), a saber: 1) La modernidad comienza en 1492 con la conquista de América, no en la llustración y/o en la revolución industrial, tal como se instaló en el discurso colonial moderno; 2) Las lógicas coloniales del poder se desparramaron capilarmente a través de un "sistema-mundo moderno/capitalista y en sus formas particulares de acumulación y de explotación a escala global" (p. 10); 3) A partir de lo anterior, se ha interiorizado la modernidad colonial es un "fenómeno planetario constituido por relaciones asimétricas de poder" (p. 10); 4) Estas relaciones asimétricas generan "una necesaria subalternización de las prácticas y de las subjetividades características de los pueblos dominados" (p. 11); 5) Dicha subalternización hunde sus raíces "en el control del trabajo y en el control de la intersubjetividad" (p. 11). 
Estos enunciados nos han permitido ir develando la trama hacia formas otras de ubicarnos en lo histórico-social, en nuestras esencias, en nuestras aprehensiones, en nuestras intersubjetividades y reconocimientos de la pluriversalidad como elemento sustancial.

Lo anterior nos da paso hacia la decolonialidad del ser/estar, saber y poder. Yendo concretamente a la decolonialidad del saber, más allá de la imbricación constante de todas las (de)colonialidades, en el punto que sigue nos abocaremos a desandar cuestiones tales como: ¿Qué es el hacer decolonial y cómo se diferencia de la investigación colonial moderna? ¿Qué son las acciones / huellas decoloniales en este hacer decolonial enmarcado en procesos decolonizadores?

\section{Acciones / Huellas Decoloniales desde Nuestro Hacer Decolonial}

Tal como hemos planteado, la perspectiva decolonial nos posibilita y alienta a desapropiarnos de las lógicas modernas impuestas por la colonialidad del ser/estar, poder y saber. Ello nos da lugar a la producción y visibilización de pensamientos y saberes otros. En este escenario, se vuelve necesario preguntarnos: ¿Cómo aproximarnos a la realidad desde el hacer decolonial? ¿Cómo superar lógicas coloniales instituidas que producen y reproducen asimetrías entre sujetos/as plurales? En primer lugar, creemos que las colonialidades del saber, aún muy ancladas en nuestras ciencias sociales y humanas, nos hacen reproductores/as de las lógicas de poder del gran capital moderno colonial. Esto no nos debería desplazar y/o paralizar en la búsqueda incesante y esencial de objetivación / subjetivación. Sin embargo, sí implica interpelarnos, una y otra vez, ante posibles sumisiones que nos tensionan. En este sentido, los espacios académicos del Sur Global nos convocan hacia la construcción singular y colectiva de marcos teórico-metodológicos, ético-políticos y epistemológico-ontológicos otros (Míguez, 2021).

En nuestros procesos decolonizadores, a través del hacer decolonial, las producciones de conocimientos se hacen colectiva y recíprocamente, nos encuentra en formas otras de pensar(nos), conocer(nos), reflexionar(nos) sobre las tramas de lo histórico-social en nuestras particularidades comunitarias. Por esta razón emergen acciones / huellas decoloniales como configuraciones que reafirman nuestras identidades, trascendiendo "las técnicas cualitativas y hermenéuticas de investigación (que) no dan respuesta a las necesidades del ser subalterno y colonizado" (Ortiz y Arias, 2019, p. 158). Es decir, resultan superadoras de las lógicas de señorío y extractivismos del "saber científico" de la modernidad colonial, donde "el "investigador" observa y pregunta, pero no le permite observar ni preguntar al "investigado". Se ve a sí mismo y excluye al otro, lo niega y opaca con su voz" (Ortiz y Arias, 2019, p. 16).

Desde de las acciones / huellas decoloniales desplegamos formas otras de encuentro, tanto entre los/as sujetos/as como en la aproximación a la realidad social: "El trabajo de campo es entonces mucho más que una simple colecta de datos, se vuelve un proceso de co-interpretación colectiva" (Olivera, 2014, p. 143). Ortíz y Arias (2019) nos plantean tres acciones / huellas decoloniales: conversar alternativo, contemplar comunal y reflexionar configurativo.

Con relación al conversar alternativo, Ortiz y Arias (2019) lo identifican como "un conversar afectivo y reflexivo, sin supuestos, sin expectativas, sin a priori, sin condiciones, permitiendo que "el otro" también pregunte y exprese sus emociones, juicios y valoraciones" (p. 158). Asimismo, en los entramados comunitarios particulares pueden surgir formas otras de materializar estos conversares alternativos, acordados previamente entre los/as participantes de los mismos. En países como Uruguay y Argentina, por ejemplo, se nos enriquece el encuentro si lo desplegamos en un "...visitar-conversando con ronda de mate, bien útil igualmente para desarmar malentendidos. (...) práctica ritual, circular y horizontal, que es el conversar con el bastón de la palabra, empleada cuando se trata de temas sensibles como para hablarlos con sinceridad desde el corazón" (Olivera, 2014, p. 148) 
En cuanto al contemplar comunal, Ortiz y Arias (2019) lo definen como "un sentir escuchar - vivenciar - observar decolonial, un escuchar-percibir-observar colectivo. (...). Es un contemplar emotivo-colaborativo, es decir un co-contemplar..." (p. 159). Ello nos da la posibilidad de registrar contextos, realidades, dichos y hechos, siendo todos/as protagonistas y constructores/as de nuestros saberes.

El reflexionar configurativo nos invita a decolonizar la praxis concreta, en el mismo hacer decolonial. Según Ortíz y Arias (2019), implica volver a "flexionar", realizar procesos de introspección para dejar a un lado los viejos instituidos coloniales. El hacer decolonial no nos deslinda de la responsabilidad de revisar nuestros a priori para superarlos, ya que "por nuestras venas corre la colonialidad del saber, el poder, el ser y el vivir. Es muy difícil configurar la paz sin descolonizar el saber y el vivir" (Ortiz y Arias, 2019, p. 152).

Estas acciones / huellas decoloniales forman parte esencial de los procesos decolonizadores de nuestro hacer decolonial. Procesos respetuosos que incorporan formas otras de producir conocimientos, sin colonizar extractivamente a los/as sujetos/as ubicados/as dentro de lo que sería el "muestreo". Para ello, se nos vuelve sustancial recuperar la curiosidad y la improvisación, resignificando lo genuino y la riqueza de lo espontáneo, soltando métodos estructurados y estructurantes elaborados previamente y planteados como únicos posibles de una manera unidireccional y jerárquica. Esto nos implica continuar tomando distancias del "saber científico" etno/eurocéntrico colonial para continuar nuestros trazos "liberados de la retórica moderna occidental, esto es, de la ciencia o conocimiento sujeta a normas y formalismos, dando voz a otras interpretaciones culturales encubiertas, colonizadas y desprestigiadas como primitivas o místicas, por la racionalidad moderna" (Zimmerman, 2015, p. 2).

\section{A Modo de Cierre}

Como modo de cierre, que posiblemente lleve a nuevas aperturas, les invitamos a (re)pensar(nos) y (re)sentir(nos) desde la perspectiva decolonial. Como dijimos, en todo Norte Global hay un Sur, y en todo Sur Global hay un Norte, por lo que, quienes a través de los trazos precedentes fueron quedando interpelados/as por los contenidos vertidos, tienen la posibilidad de potenciar sus saberes hacia formas otras de conocer y producir conocimientos.

A lo largo del presente escrito realizamos un somero y necesario recorrido por las colonialidades del ser/estar, saber y poder, las cuales fuimos traspasando, perspectiva decolonial mediante, hacia sus decolonialidades. Hicimos especial hincapié en las (de)colonialidades del saber, en tanto son las que más nos interpelan en nuestros procesos decolonizadores, en nuestro hacer decolonial y en nuestras acciones / huellas decoloniales. Este giro decolonial, nos ha permitido (re)ubicar(nos) como sujetos/as plurales con saberes pluriversales, sin lógicas de señorío ni extractivismos.

La perspectiva decolonial nos ha posibilitado quitar el manto de nuestros ojos, pudiendo romper varias cadenas impuestas desde hace más de cinco siglos. Esto nos viene permitiendo, desde las lógicas del saber, desplegar nuestras esencias, sin demarcaciones de "valías", sin clasificaciones ni calificaciones desde aquellos/as que desde la modernidad colonial se arrogan toda posibilidad de hacer y no dejar hacer a partir de su propio ombligo. Es entender que quienes siempre hemos sido leídos/as con desconfianzas, prenociones, desencuentros, que aquellos/as que hemos sido ubicados/as en la alteridad, en la barbarie, en lo no-civilizado, en lo no-humano, simplemente hacemos a la pluralidad de sujetos en el mundo, con nuestras propias esencias de habitarlo, conocerlo y reproducirlo. Que quienes hayan escrito la "historia oficial" desde 1492 sean los/as "triunfadores/as", no lo hace una verdad absoluta, sino una imposición compleja de las colonialidades del saber.

En este escenario, el "saber científico" colonial se nos parece más a un árbol de navidad con todos sus chirimbolos y luces, reproductor de una estética colonial de encandilamiento y ceguera, más que la sustancia medular para generar saberes pluriversales a partir del reconocimientos de los/as sujetos/as según sus entramados histórico-sociales. 
Si desde nuestro Sur Global no logramos discernir formas de contenidos de este "saber científico" colonial, difícilmente podamos trascender hacia formas otras de conocer y producir conocimientos. En ese caso, solo podremos continuar reproduciendo (ya no acríticamente) lógicas investigativas coloniales, donde los/as sujetos/as de la investigación son "objetos de estudio", por tanto, objetos de las metodologías coloniales que se desplieguen. Sin embargo, desde el hacer decolonial, los/as sujetos/as plurales que hacemos parte de los procesos decolonizadores, somos sus protagonistas, somos productores/as colectivos/as de conocimientos a través del despliegue de acciones / huellas decoloniales que nos aúnan para fines concretos. Evidenciar y trascender las lógicas coloniales del saber nos permite interpelar instituidos naturalizados de una única forma de producir conocimientos, así como generar puentes hacia formas otras de reconocer(nos) como sujetos plurales ( $\mathrm{y}$, por ende, potentes) en procesos decolonizadores. Ello nos aúna hacia la construcción de sociedades otras, donde el reconocimiento, la solidaridad, la pluriversalidad, nos potencian hacia nuevos horizontes de sentidos, sin lógicas de señorío ni extractivismos.

El hacer decolonial enmarcado en procesos decolonizadores nos permite desandar caminos aprendidos y aprehendidos a diferentes niveles y escalas. No es tarea sencilla, nos implica hacer constantes esfuerzos para despojarnos y problematizar cada idea / costumbre / práctica que creemos natural, pero que, de hecho, no es nada más (ni nada menos) que la colonialidad haciendo estragos a niveles inverosímiles.

Frecuentemente, recurrir al hacer decolonial fuera de entramados decoloniales académicos, implica un doble trabajo de justificación, dado que nuestras universidades aún llevan en sus entrañas al Norte Global epistémico. Eso reproduce lógicas de señorío a la interna de nuestras universidades, quizá, más complejas que las desplegadas desde el Norte Global. Al menos, quienes investigan desde el Norte Global tienen sus contenidos interiorizados y reproducidos según sus formas de habitar el mundo, conocerlo y producir conocimiento a partir de ello. Sin embargo, nuestras universidades latinoamericanas siguen pavoneando un "saber científico" colonial que da cuenta que, muchas veces, el Norte de nuestro Sur Global es mucho más doloroso que el Norte del Norte Global. Un triunfo más que podemos acreditarle a la interiorización de las colonialidades del saber y del poder.

En consonancia con lo anterior, Ortíz y Arias (2018) nos plantean:

Decolonizar la educación significa, entre otros argumentos, reconocer que los indígenas, campesinos, afros o sordos, vienen a la universidad no solo a aprender y transformarse sino también a enseñar. La decolonialidad de la educación se logra en la misma medida en que se reconoce la validez e importancia de los saberes "otros" no oficializados por la matriz colonial (p. 200).

\section{Referencias}

Castro-Gómez, S.; Grosfoguel, R. (Comp.). (2007). El giro decolonial. Reflexiones para una diversidad epistémica más allá del capitalismo global. Siglo del Hombre Editores.

Castro-Gómez, S. (2000). Ciencias sociales, violencia epistémica y el problema de la invención del otro. In: Lander, E. (comp.). La colonialidad del saber: Eurocentrismo y ciencias sociales. Perspectivas latinoamericanas. Consejo Latinoamericano de Ciencias Sociales.

Castro-Gómez, S. (1996). Crítica de la razón latinoamericana. Puvill.

Coronil, F. (1999, enero-marzo). Más allá del Occidentalismo: Hacia categorías geohistóricas no imperiales. Casa de las Américas.

De Sousa Santos, B. (2012). De las dualidades a las ecologías. REMTE - Cuadernos de Trabajo.

De Sousa Santos, B. (2010). Para descolonizar Occidente. Más allá del pensamiento abismal. Clacso. 
Dussel, E. (1994). 1492: el encubrimiento del otro : hacia el origen del mito de la modernidad. UMSA.

GESCO. (2010, julio-setiembre). Modernidad / colonialidad / decolonialidad: aclaraciones y réplicas desde un proyecto epistémico en el horizonte del bicentenario. Pacarina del Sur.

Grosfoguel, R. (2016, enero-junio). Del «extractivismo económico» al «extractivismo epistémico» y al "extractivismo ontológico»: una forma destructiva de conocer, ser y estar en el mundo. Tabula Rasa.

Hermanos Berbel. (s/d). Amutuy. s/d. (canción).

Lander, E. (comp.). (2000). La colonialidad del saber: eurocentrismo y ciencias sociales. Perspectivas latinoamericanas. CLACSO.

Maldonado Torres, N. (2008, julio-diciembre). La descolonización y el giro des-colonial. Tabula Rasa.

Meneses, MP. (2018, Noviembre). Colonialismo como violência: a "missao civilizadora" de Portugal em Moçambique. Revista Crítica de Ciências Sociais, Número especial. Centro de Estudos Sociais da Universidade de Coimbra.

Mignolo, W. (2010). Desobediencia epistémica: retórica de la modernidad, lógica de la colonialidad y gramática de la decolonialidad. Del Signo.

Míguez, MN. (2021). Del análisis de discursos colonial al diálogo de saberes decolonial. WCQR2021. (en proceso de publicación)

Míguez, MN. (2020). Análisis de discursos desde la perspectiva decolonial. CIAIQ2020.

Montano, R. (2018, enero-mayo). El ego conquiro como inicio de la modernidad. Quintana Roo: Teoría y Praxis, Vol.16(32).

Olivera, A. (2014, febrero-mayo). Etnografía decolonial con colectivos charrúas: reflexionando sobre interconocimientos. Revista Antropología Social y Cultural del Uruguay, Vol.12.

Ortíz Ocaña, A.; Arias López, MI. (2019, enero-junio). Hacer decolonial: desobedecer a la metodología de investigación. Hallazgos, Vol. 16(31).

Pereira Lázaro, JP. (2017, abril - junio). La retórica de la modernidad, la lógica de la colonialidad y la globalización en el ámbito de las migraciones transnacionales: formación de subjetividades negadas y cotidianidad del migrante del sur. Pacarina del Sur - Revista de Pensamiento Crítico Latinoamericano, Vol. 8 (31).

Quijano, A. (2007). Colonialidad del poder y clasificación social. In: Castro-Gómez, S.; Grosfoguel, R. (Comp.). El giro decolonial. Reflexiones para una diversidad epistémica más allá del capitalismo global. Siglo del Hombre Editores.

Rodríguez, S. (1968). La era está pariendo un corazón. Silvio Rodríguez Producción. (Canción)

Walsh, Catherine (2007, abril). ¿Son posibles una ciencias sociales/ culturales otras? Reflexiones en torno a las epistemologías decoloniales. Nómadas.

Zimmermann, L. (2015). Lectura y pensamiento decolonial: aportes del análisis del discurso para la lectura de textos. In: Actas Congreso Nacional Subsede Cátedra Unesco UNR. Universidad Nacional del Litoral. 